\title{
BEINVLOEDING DER VEERPAPILLEN.
}

\section{$A$. Uitwendige beinvloeding der Veerpapillen.}

Gedurende de wintermaanden van het jaar 1913 op 1914 was ik in de gelegenheid een paar jonge Donkere-goudfazanten, die toen ongeveer den leeftijd van $41 / 2$ maand bereikt hadden, te laten overwinteren in de verwarmde serre der anthropomorphe apen van den Zoologischen Tuin te Amsterdam. De beide vogels (A), een haan en een hen (Thaumalea obscura), waren dus in Juni 1913 geboren. De haan vertoonde het jeugdkleed, bezat dus donkere, dwarsgebande veeren en was niet in prachtkleur, daar deze dieren eerst omstreeks de 13de levensmaand het typische, manlijke kleed verkrijgen.

Het lag in mijn bedoeling om te onderzoeken of er. en zoo ja welke invloed op het eierleggen der hen, op den rui bij haan en hen en op het veerpatroon zou worden uitgeoefend. Het is aan alle kweekers van hoenders bekend, dat men door kunstmatige belichting, den dag als 't ware verlengend, de vogels productiever maken kan. Deze productiviteit bestaat natuurlijk in het leggen van meer eieren. Dit verschijnsel schijnt, naar de meening der hoenderkweekers, hoofdzakelijk te berusten op een kunstmatige dagverlenging, welke een overvloediger toedienen van voedsel toelaat. Naar hun meening berust derhalve het leggen van meer eieren geheelenal op de grootere hoeveelheid voedsel. Het wil mij voorkomen, dat het niet uitgesloten zou zijn, dat er behalve door de grootere voedselhoeveelheid ook invloed zou worden uitgeoefend door de langere belichting. Indien de belichte, levende wezens althans geen dieren, maar planten zijn, zal wel niemand meer aan den invloed van het licht twijfelen. Dit was een der redenen, waarom ik de beide vogels aan deze proef onderwierp, maar nog andere redenen waren er, welke ik zoo dadelijk puntsgewijs toelichten zal.

Mijn controle-proef werd genomen met een 20-tal andere, eveneens halfjarige, donkeregoudfazanten (B), waaronder ook verscheidene hanen. Deze vogels brachten den winter door in de buitenlucht en wel in koude, onverwarmde volières, waaraan eveneens onverwarmde en open nachthokken verbonden zijn. De proefneming verliep nu aldus:

A. De voorwaarden, waaronder de beide serre-vogels den winter doorbrachten, zijn de volgende:

$1^{\circ}$. De temperatuur was ongeveer $22^{\circ}$ Celsius en bleef vrijwel constant.

$2^{\circ}$. De belichting bestond uit zwak, electrisch licht van 's morgens ongeveer 7 uur, totdat het helder dag werd, vervolgens daglicht, totdat de duisternis inviel, en daarna, dus van ongeveer 3 uur 's middags, wederom zwak, electrisch licht tot ongeveer 's avonds half vijf.

$3^{0}$. De athmospheer was vochtig. In de serre wordt een paar maal daags gespoten.

B. De voorwaarden, waaronder de volière-vogels den winter doorbrachten, zijn de volgende:

$1^{0}$. De temperatuur was ongeveer $2^{\circ}-5^{\circ}$. Celsius. Ze bleef volstrekt niet constant, daar er o. a. een flinke, veertiendaagsche vorst intrad, waarbij de thermometer daalde tot 
ongeveer $-4^{1} /_{2}^{\circ}$ Celsius. Bovendien vonden er allerlei temperatuur-schommelingen plaats.

$2^{0}$. De belichting bestond slechts uit daglicht en duurde dus verscheidene uren korter dan de belichting der beide serre-vogels.

$3^{0}$. De athmospheer was vochtig, behalve natuurlijk gedurende de korte periode van vorst.

In de eerste plaats komt dus het groote warmteverschil, dat men gemiddeld op $18^{\circ}$ Celsius stellen mag, en in de tweede plaats het belichtingsverschil in aanmerking voor het optreden van eventueele verschillen tusschen beide soorten van dieren (A en B).

De beide jonge vogels (A) werden op den 20sten November 1913 in de anthropomorphen serre ondergebracht en hielden daar verblijf tot den 10den April van het volgend jaar. Wanneer men nu weet, dat omstreeks half April het eierenleggen bij de goudfazanten een aanvang neemt, en dat in verband daarmede ongeveer één maand later de hanen en $2 \%$ tot 3 maanden later de hennen in den rui komen, dan mocht men dus bij optreden van verschil verwachten, dat dit ontstaan zou vóór den 10den April. Indien dus de veerpapillen even gemakkelijk als planten door uitwendige omstandigheden waren te beinvloeden, dan mocht men aannemen, dat er zich voor dien datum verschil in het uiterlijk der serre-vogels eenerzijds en der volière-vogels andererzijds zou opgetreden zijn.

Deze proef wees echter een volkomen negatief resultaat uit. Immers, toen ik de beide serrevogels den $10^{\text {den }}$ April in de buitenlucht bracht, was het hennetje nog niet aan den leg en geen der beide vogels vertoonde een spoor van rui. In het veerenpatroon was geen verschil opgetreden. Zelfs was de serre-haan (A) den 3den Juni 1914 niet verder in den rui dan zijn volière-broeders (B). Hij kwam eerst tegelijk met de anderen, in Augustus van dat jaar, op kleur. Ook toen kon ik nergens eenig opmerkelijk verschijnsel in het veerpatroon vinden. Hetzelfde moet van de serre-hen gezegd worden.

De mogelijkheid, dat deze met slechts twee vogels genomen proef geen voldoende zekerheid geeft, bestaat zonder twijfel: Waar de mogelijkheid niet uitgesloten is, dat een proefneming met meerdere vogels tot een ander resultaat geleid zou hebben, wat ik echter volstrekt niet durf te beweren; is dus nu slechts aangetoond (maar dit dan ook met zekerheid), dat de beinvloeding der veerpapillen door warmte (eventueel ook door licht) een vrij geringe is. Het is immers volstrekt niet aannemelijk, dat de gekozen vogels juist een paar voor deze studie zeer ongeschikte dieren waren. Uit het feit, dat zij niet reageerden, mag men dus tot een geringen invloed dezer uitwendige factoren besluiten. Het blijft echter volstrekt niet uitgesloten, dat een meerjarige of een nog intenser beinvloeding zich wel degelijk had doen gelden.

Op de hier boven besproken wijze was het mij dus niet mogelijk eenige veranderlijkheid der veerpapillen aan te toonen. Zoo dadelijk zal ik terugkomen op de redenen, welke mij tot het doen dezer proef aanleiding gaven, en op het doel, dat ik ermede verwachtte te bereiken.

In den zomer van 1913 was ik in de gelegenheid een interessante waarneming te doen bij acht Kanoet-strandloopers (Tringa canutus). De Kanoet-strandlooper wordt genoemd als een der bekende voorbeelden van kleurwisseling der veeren zonder veerrui. Dit zonderling verschijnsel, dat wij ook bij den Toerako (Turacus) en bij het Schotsche Sneeuwhoen (Lagopus scoticus) vermeld vinden, en dat, naar het schijnt, nog veel algemeener verbreid is, is ondanks enkele uitvoeriger onderzoekingen nog steeds in een geheimzinnig duister gehuld. Nog steeds blijft het onbegrijpelijk, hoe een dood element, een doode veer, in staat is van uiterlijk te veranderen. Helaas ben ik zelf niet in staat geweest een onderzoek, dat ik daaromtrent deed bij Kemphaantjes (Pavoncella pugnax $\sigma^{\top} \sigma^{\top}$ ), ten einde te brengen, doordat de vogels, wier veeren ik verzameld had, bij het tweede onderzoek allen door ratten weggevangen waren. Ik was nog niet in de gelegenheid dit onderzoek te herhalen.

Ik wil echter terugkomen op de zoo straks genoemde waarnemingen bij acht Kanoetstrandloopers. De Kanoet-strandlooper vertoont onder gewone omstandigheden het volgende uiterlijk: In Mei bezitten de vogels een roode borst. Hun borst wordt in Juni lichter en grijs van kleur. In Juli treden er op schouder en rug vlekjes op. Zoo is dus het normale 
verloop van zake. De data zijn slechts bij benadering opgegeven. De acht bovenbedoelde strandloopers nu werden om redenen van huishoudelijken aard in het vroege voorjaar opgesloten in een goed verlichten, maar niet-zonnigen stal. Gedurende den geheelen zomer bleven ze daar gehuisvest en eerst in het daaropvolgend najaar kwamen de vogels weer in de buitenlucht. Gedurende voorjaar en zomer vertoonden de veeren der vogels een egaal-donkere kleur, terwijl de wisselingen in rood en het aannemen van vlekjes geheel achterwege bleven. Toen de vogels in het najaar buiten gekomen waren, bleekten ze allen spoedig op. Ik kan niet nader aangeven, welke de omstandigheid was, welke de vogels het donkere uiterlijk deed aannemen, en die hen uitsloot van de kleurwisselingen. Naar het mij echter voorkomt, blijkt er uit deze waarneming met zekerheid, dat er door een uitwendige beinvloeding der vogels (of der veerpapillen) een wijziging mogelijk is in het normale verloop der gebeurtenissen. Daar het, ook indien de patroon- of kleurverandering niet op veerrui, maar op iets anders berust, toch waarschijnlijk is, dat de veerpapil de wijzigingen tot stand brengt, mag men dus in dit geval aannemen, dat de veerpapil door de uitwendige beinvloeding tot wijziging van haar normale gedrag gebracht werd. Geheel zeker is het echter niet. Immers men kan zich ook een kleurwisseling op zuiver-chemischen grondslag denken.

Er rest mij nu nog mededeeling te doen van de redenen, welke mij tot het nemen van deze proef met fazanten brachten. Het was mij. opgevallen, dat een leeftijdsverschil van 1 tot $1^{1 / 2}$ maand bij jonge goudfazanten ten gevolge heeft, dat het veerpatroon een iets meer gevorderd stadium verkrijgt. Terwijl jonge hanen van $2 \frac{1}{2}$ maand in den herfst een jeugdkleed bezitten, waarin de gouden kleur nog in 't geheel niet optreedt, zijn hanen, welke slechts één maand ouder zij̄n, o. m. voorzien van een min of meer bruin-gouden kuif. Een dergelijk verschil van patroon in verband met den leeftijd treedt bij vele fazanten op. Ik hoopte dus in staat te zijn om door toevoer van warmte en licht de vogels tot een vervroeging van den voorjaarsrui te brengen, en zoodoende een veerkleed van een ongeveer halfjarigen vogel te verkrijgen. Wanneer dit gelukte, bestond er kans, dat het veerkleed een overgangsvorm zou worden tusschen het jeugd-kleed en het volwassen-kleed. Maar ook dit was niet zeker, daar men door de kunstmatige bespoediging van den rui misschien tegelijkertijd de invloeden, waarop het patroon der veeren berust, forceert en dus als 't ware tegelijkertijd bespoedigt. Hoe dit nu zij, de proef had, gelijk gezegd, een negatief resultaat.

\section{B. Inwendige beinvloeding der Veerpapillen.}

Onder inwendige beinvloeding der veerpapillen versta ik den invloed, welke door innerlijke oorzaken op de papillen worden uitgeoefend. Het zijn dus in de eerste plaats invloeden uitgeoefend door de voeding en door de innervatie. Ik trachtte door middel van transplantaties deze invloeden te wijzigen. Dit hoofdstuk zal dus handelen over de poefnemingen met transplantatie, waarmede ik de vraag aangaande de meerdere of mindere fixatie der veerpapil bij lichamelijk-volwassen vogels trachtte op te lossen. De vraag, welke ik hierbij dus stelde, luidt aldus:

Is bij een lichamelijk-volwassen vogel elke veerpapil genoodzaakt om een bepaalde veer (naar vorm, kleur en teekening) voort te brengen, of wel is de specialisatie der veerpapil nog niet zoover doorgevoerd en is zij derhalve in staat een andere als de normaliter voort te brengen veer te doen uitgroeien?

Tot het stellen dezer vraag komt men vanzelf bij de studie van het veerkleed van een vogel. Hierbij vindt men immers zoo tallooze overgangen (naar vorm, kleur en teekening) tusschen twee uitersten van veertypen, dat men zich als ' $t$ ware tot de meening gedrongen ziet, dat de veeren niet een eigen, een individueel beeld bezitten, maar dat zij slechts onder- 
deelen uitbeelden van een grooter geheel en dus ieder een klein onderdeel vertoonen van een grooter, en dieper wortelend patroon ( $n^{0}$. 5). In het "Overzicht" wil ik daar ook nader op terug komen. De vraag kan derhalve nog op andere wijze gesteld worden:

Indien men in staat was een bepaalde veerpapil van het diepere patroon los te maken, welken invloed zou dit dan uitoefenen op den vorm, de kleur en de teekening van de later. te ontwikkelen veer?

Deze vraag lijkt mij te meer gerechtvaardigd, cmdat juist het groote aantal en de groote, gradueele verscheidenheid der overgangsveeren tusschen twee veertypen in sterke mate het vermoeden wekken, dat een bepaalde veerpapil evenzoogoed het eene als het andere veertype had kunnen doen uitgroeien en dat slechts de toevallige plaatsing dier veerpapil, in verband met het diepere patroon, haar belette om in een dier uitersten of in iets heel anders misschien te vervallen. Het is hier niet de plaats deze vraag uitvoerig te bespreken. In het "Overzicht" kom ik daarop terug. Het is hier voldoende op te merken, dat deze vraagstelling mij tot het doen van transplantatie-proeven bracht.

Door transplantatie-proeven poogde ik dus de veerpapil van haar oorspronkelijk, dieper wortelend patroon los te maken. Als studiemateriaal koos ik jonge goudfazanten-hanen. Voor een der proeven nam ik echter, om redenen van praktischen aard, een patrijskriel-haan, die aan dezelfde eischen voldeed, welke ik aan de goudfazanten gesteld had. Het dier stierf echter onder de narcose.

Ik wil even de noodzakelijke mededeelingen doen omtrent het opkleurkomen der goudfazanten-hanen. Deze vogels verkrijgen op een leeftijd van 13 tot 14 maanden hun volle kleur en wel als gevolg van een rui. Deze volle kleur bestaat op de rugzijde in hoofdzaak uit een gouden kuif, een oranje kraag, een groene schouder- en halsbedekking, een gouden zadel enz. Van deze schitterende kleuren is bij een haan van 11 tot 12 maanden geen spoor te zien. Desniettegenstaande is de vogel reeds tot voortplanting geschikt. Deze hanen zijn dus geslachtelijk reeds geheel volwassen. Om meerdere redenen leken mij nu deze vogels voor mijn transplantatie-proefneming bijzonder geschikt. Immers:

$1^{0}$. Men werkt met volwassen, dus met krachtige dieren.

$2^{\circ}$. De kans, dat de fixatie of specialisatie der veerpapillen bij nog niet op kleur gekomen vogels niet heeft plaats gevonden, is $m$. i. hier grooter dan bij geheel op kleur gekomen vogels. Vindt men hier dus reeds de differentatie voltooid, dus m.a.w. een onvermogen om iets anders als het vooropgezette te produceeren, dan mag men dit waarschijnlijk bij oudere, reeds op kleur gekomen vogels ook aannemen.

$3^{0}$. Het was mij uit eigen, meerjarige ondervinding bekend, dat fazanten groote huidwonden gemakkelijk verdragen en er spoedig van genezen. Het komt n.l. jaarlijks geregeld in den paartijd voor, dat de hanen aan de hennen groote, soms vingerlange wonden op kop en rug toebrengen. Ook vechten de hanen in het voorjaar hevig onder elkaar. Hierbij is het mij opgevallen, dat de vogels, ondanks die vreeselijke verwondingen, meestal niet alleen het leven behouden, maar dat de wond, na een vrij ruwe hechting en een betrekkelijk onzorgvuldige behandeling, haast onzichtbaar en zonder spoor van lidteeken geneest, terwijl het broeden zelfs na korte onderbreking kan worden voortgezet.

$4^{0}$. Bij de veeren der goudfazanten-hanen doet zich een zeer goede omstandigheid voor. De hanen vertoonen n.l. een groen schouderveld en een gouden zadel. Wij vinden dus twee zeer ongelijike veervelden dicht bij elkaar en wel op den rug. Men heeft hier bovendien geen last van allerlei storende invloeden als daar zijn : het invallen van stof of zand in de wond, een ongewenscht schuren of pikken in de wond door den vogel zelf, of wel het rekken en verschuiven van de huid door de natuurlijke bewegingen van den vogel. De rug biedt werkelijk de beste voorwaarden voor een goede genezing.

$5^{0}$. Men vindt weliswaar tusschen het groene en het gouden veld, gelijk overal elders, allerlei geleidelijke overgangsvormen, maar deze overgangsveeren beslaan tusschen deze beide velden slechts een zeer korten afstand en de meeste groene veeren 
gelijken dus in het geheel niet op de gouden veeren van het zadel. Men behoeft derhalve niet al te nauwkeurig toe te zien, of men wel precies de middelste, dus meest-typische veeren van een veld verplaatst. Dit zou trouwens bij de nog niet opgekleurde hanen niet wel mogelijk zijn uit te maken. Men kan slechts bijj benadering, maar overigens met voldoende zekerheid, bij den niet-opgekleurden vogel aangeven, waar de groene schouderveeren en waar de gouden zadelveeren later zullen optreden.

Ik ben nu volgens drie methoden te werk gegaan om de groene schouderveeren en de gouden zadelveeren met elkaar van plaats te doen verwisselen. In dit speciale geval luidde dus mijn vraag:

Blijven na transplantatie van de groene-veeren-dragende schouderhuid naar het goudenveeren-dragende zadel de veerpapillen groene veeren ontwikkelen, of wel ontwikkelen zij na de verplaatsing gouden veeren of misschien zelfs anders-gekleurde veeren? Dezelfde vraag kan evenzoogoed aangaande de gouden zadelveeren gedaan worden.

De drie methoden van transplanteeren, die ik in toepassing bracht, zijn de volgende:

a. Men snijdt een stuk huid uit het groene veld en een even groot stuk uit het gouden veld en verwisselt beiden.

b. Men snijdt een tongvormigen lap huid (met de lengteas in de lengterichting van den rug verloopend en aan een der korte zijden dus niet afgesneden). Men ligt dezen tongvormigen lap met een scherp mes van het ondergelegen weefsel af. De tongvormige lap is nu zoo gekozen, dat hij zoowel in het groene als in het gouden veld reikt. Hij is vastgehecht gebleven aan de korte zijde, welke in het groene veld gelegen was. De lengte van den lap was ongeveer 8 centimeter, de breedte ongeveer 2 centimeter. Van dezen 8 centimeter langen lap werd het topstuk (behoorende dus tot het gouden veld), ongeveer $21 / 2$ centimeter lang, afgesneden en weggeworpen. De overblijvende huid, ongeveer $5{ }^{1} / 2$ centimeter lang, werd uitgerekt over de geheele wondlengte (8 centimeter) en vervolgens vastgenaaid. Daar de omliggende huidranden allen aan hun oorspronkelijken ondergrond vastgehecht bleven, kwam dus de uitrekking in hoofdzaak ten laste van het tongvormige stuk. Dit had dus een verplaatsing der veerpapillen vanuit het groene naar de plaats van het gouden veld bewerkstelligd. De voeding der van onderen losgemaakte huid kon door de niet-afgesneden, korte zijde voortdurend plaats vinden (steeltransplantatie).

c. Men snijdt een stuk huid (lengteas in de lengte van den rug verloopend) geheel los en ligt het van den ondergrond af. De lengte van den lap was ongeveer 8 centimeter, de breedte ongeveer 2 centimeter. Ik had het stuk zoo gekozen, dat het zoowel veerpapillen van het groene schouderveld als van het gouden zadelveld bevatte. Het geheel losgemaakte stuk huid werd opgelicht, vervolgens $180^{\circ}$ omgedraaid en op dezelfde plaats weer vastgehecht. Het gevolg hiervan is dus, dat het verplaatste, groene veld hoofdzakelijk op de plaats van het gouden veld terecht kwam en dat omgekeerd het gouden veld op de plaats van het groene veld werd bevestigd. Bovendien is een niet onbelangrijk gevolg, juist van deze wijze van opereeren, dat de veeren achterstevoren geplaatst worden. Dit laatste bleek van groot voordeel bij de latere herkenning van het getransplanteerde huidstuk. Immers de vergroeiing blijkt zoo volmaakt te zijn, dat er na een paar maanden geen spoor van eenig lidteeken te vinden was.

Gelijk gezegd, de transplantaties vonden plaats kort voor den aanvang van den rui en wel bij jonge hanen; die nog het jeugdkleed droegen. Soms waren er klaarblijkelijk reeds enkele veeren uitgevallen en er vertoonden zich daarvoor in de plaats bloedpennen, welke als stekels buiten de huid uitstaken. Deze weinige, jonge bloedpennen gingen allen zonder uitzondering na de operatie dood. Ik koos het tijdstip vlak voor den rui, omdat de groote bloedaandrang naar de huid toe (gedurende den rui) een goede voorwaarde scheen voor een goede voeding van de losgesneden huid. Ik meende, misschien ten onrechte, uit de geweldige verandering, welke met die bloedaandrang samenhangt, de conclusie te mogen trekken, dat 
daarmede het tijdstip van nieuwe patroonsbepaling zou samenvallen. Bovendien is het warme jaargetijde (begin Juni) eveneens een belangrijke factor voor. het goede verloop van de proef.

Volgens elk der drie methoden werd een vogel behandeld. Ik was zoo gelukkig, dat twee der drie vogels in leven bleven en dat de getransplanteerde huid zich goed vasthechtte. Een kort verslag daarover wil ik hier doen volgen.

Voor de operatie werden de vogels bevestigd op een plankje en wel zoodanig, dat zij zich geheel niet verroeren konden en dat toch hun ademhaling niet belemmerd werd. Daarna werden alle schouder- en rugveeren voorzichtig verwijderd. De enkele, reeds vermelde bloedpennen bleven echter staan. Zij dienden ter orienteering en het verwijderen dezer pennen zou bovendien een noodelooze pijn en een ongewenschte bloeding hebben veroorzaakt. Daarna werd de naakte vogelhuid zorgvuldig met aether gereinigd. De operatie vond vervolgens plaats onder aether-narcose en verliep, dankzij het gebruik van de operatie-kamer van het Physiologisch Laboratorium, zooveel mogelijk aseptisch. De duur der narcose bedroeg ongeveer 20 minuten.

De volgens methode $a$. behandelde haan stief helaas in de narcose. Een herhaling dezer methode van transplanteeren bleek gelukkig overbodig, daar de methoden $b$. en $c$. beiden naar wensch slaagden. De dieren genazen vlug en de verplaatste huid bleef grootendeels in leven. Na $1 \frac{1}{2}$ maand bleken de beide hanen geheel hersteld te zijn, en waren er op de kaal geplukte huid nieuwe veeren uitgegroeid. Deze veeren vertoonden duidelijk kleur en teekening. De volgens methode $b$. behandelde haan droeg nu een verlengd, groen schouderveld. De door de uitrekking verplaatste, groene veerpapillen hadden dus ook na de operatie groene veeren doen ontstaan. Bij den volgens methode $c$. behandelden haan waren dertien veeren opgekomen en wel twaalf gouden en een groene. Deze veeren stonden allen achterstevoren, de groene stond in het zadelveld, de gouden hoofdzakelijk in het schouderveld. De veeren hadden dus haar oorspronkelijke kleur behouden of m. a. w. de veerpapillen hadden na de transplantatie geen andere als de voor haar typische veeren doen uitgroeien. Later ontwikkelden zich meerdere groene veeren op het verplaatste, groene huidstuk.

Het schijnt dus, dat op den leeftijd van 12 maanden de buid reeds geheel volgens bepaalde velden gedifferentieerd is, hoewel dit uiterlijk, voornamelijk zoover het kleurvelden betreft, op de meeste plaatsen niet of nauwelijks te zien is. Het onderliggende weefsel, hiervoor zullen dan in de eerste plaats wel de zenuwen in aanmerking komen, schijnt op dezen leeftijd geen invloed meer uit te oefenen op het patroon en de kleur der veeren. Men mag immers aannemen, dat bij het weder vastgroeien van de getransplanteerde huid nieuwe bloedvaten een verbinding vormen met het onderliggende weefsel, en dat met deze bloedvaten de uiterste vertakkingen van het zenuwstelsel mede weder indringen in het losgesneden huidstuk. Indien dus een beinvloeding door de zenuwen mogelijk is, zouden na de transplantatie andere als de oorspronkelijke zenuwen de veeren hebben geinnerveerd. Op grond daarvan had men een ander veerbeeld mogen verwachten. Het veerkleed bleek evenwel onveranderd.

De mogelijkheid blijft echter nog open, dat de transplantatie te laat plaats vond en dat de papillen reeds het veerpatroon hadden gefixeerd, zoodat dus eerst bij een volgenden rui de aanpassing aan de nieuwe inplantingsplaats tot stand komen kan. In afwachting daarvan heb ik den volgens methode $c$. behandelden haan, welke nog leeft, een afzonderlijke ren gegeven.

Uit deze proeven blijkt derhalve, dat het nog onzeker is, of de verplaatsing der veerpapillen invloed kan uitoefenen op de later te ontwikkelen veeren.

\section{Conclusies aangaande de beinvloeding der Veerpapillen.}

Vergelijkt men de conclusies, welke men uit het feitenmateriaal mag trekken, met de conclusies, welke nu uit dit meer proefondervindelijk onderzoek volgen, dan komt men met 
de hier verstrekte gegevens weliswaar niet tot een tegenstrijdigheid, doch evenmin mag men zeggen, dat ik hiermede tot een bevredigend einde gekomen ben. De zuivere veerbeschouwing van Argusianus ( $\mathrm{N}^{0}$. 4.) en Pavo (No. 5.) toonden onweerlegbaar aan, dat het mogelijk moet zijn, dat een veerpapil een andere als de voor haar normale veer doet ontstaan. Een toevallig genomen proef of waarneming bij Tringa canutus schijnt deze gevolgtrekking ten volle te bevestigen. De door mijzelf ingestelde serre-proef en de eveneens door mij ingestelde transplantatie-proeven schijnen tot geen en misschien zelfs tot een negatief resultaat te leiden. Daar echter de eerstgenoemde feiten zoo duidelijk spreken, moet men wel tot de slot-conclusie komen, dat een veerpapil toch een zekere vrijheid heeft om een andere als de voor haar normale veer te doen ontstaan, maar dat de voorwaarden, waaronder zich die vrijheid toonen kan, vooralsnog onbekend gebleven zijn. In het „Overzicht" wil ik hierop nader terugkomen.

Hier moge nog eens herhaald worden, dat de zoo opvallende differentatie van de veeren naar vorm, teekening en kleur, in verband met haar plaats van inplanting op het vogellichaam en mede in verband dus met de andere veeren van denzelfden vogel, de naaste aanleiding is geweest voor het instellen van het boven besproken onderzoek. 